\title{
Genitives, Relational Nouns, and the Argument-Modifier Distinction $^{1}$
}

\author{
Barbara H. Partee, University of Massachusetts \\ Vladimir Borschev, VINITI, Russian Academy of Sciences \\ partee@linguist.umass.edu, borschev@online.ru
}

\begin{abstract}
The argument-modifier distinction is less clear in NPs than in VPs; nouns do not typically take arguments. The clearest cases of arguments in NPs are in certain kinds of nominalizations which retain some "verbal" properties (Grimshaw 1990). The status of apparent arguments of non-deverbal relational nouns like sister is more controversial.

Genitive constructions like John's teacher, team of John's offer a challenging testing ground for the argument-modifier distinction in NPs, both in English and cross-linguistically. On the analyses of Partee (1983/97) and Barker (1995), the DP in a genitive phrase (i.e. John in John's) is always an argument of some relation, but the relation does not always come from the head noun. On those "ambiguity" analyses, some genitives are argument-like and some are modifier-like. Recent proposals by Jensen and Vikner and by Borschev and Partee analyze all genitives as argument-like, a conclusion we are no longer sure of.

In this paper we explore a range of possible analyses: argument-only, modifier-only, and ambiguity analyses, and consider the kinds of semantic evidence that suggest that different analyses may be correct for different genitive or possessive constructions in different languages.
\end{abstract}

\section{The argument-modifier distinction in NPs}

The argument-modifier distinction is less clear in NPs than in VPs; nouns do not typically take arguments. The clearest cases of arguments in NPs are in some nominalizations (Grimshaw 1990). Non-deverbal relational nouns like sister, mayor, enemy, picture, edge, height in some sense also seem to take arguments. C.L.Baker (1978) proposed a test using English one anaphora: one substitutes for N-bar, which obligatorily includes all of a noun's arguments. By that test, (1a) to Oslo is a modifier, while of Boston in (1b) is an argument. But neither this nor any other known test has seemed conclusive, and the question of whether and in what sense "true nouns" take arguments remains controversial.

(1) a. The train to Oslo takes longer than the one to Stockholm.

b. *The mayor of Boston has more power than the one of Baltimore.

\footnotetext{
1 The authors wish to thank many colleagues for suggestions and discussion, especially Carl Vikner, Per Anker Jensen, Elena Paducheva, and Ekaterina Rakhilina. In addition to the conference in Oslo for which this paper was prepared, parts of this material were presented by one or both authors in graduate courses in Leipzig, Potsdam, Kolding, Moscow, and Prague, in a reading group at UMass Amherst, and in lectures in Berlin, Munich, Kleinwalsertal, Austria, at ESCOL 1999, in Bloomington, Swarthmore, and Tel Aviv. We are grateful to members of those audiences for useful suggestions. We thank Ji-Yung Kim for assistance with preparation of the final manuscript. The first parts of this paper overlap substantially with the first parts of Partee and Borschev (in press a).

This material is based upon work supported by the National Science Foundation under Grant No. BCS9905748.
} 
Genitive $^{2}$ constructions like those in $(2 \mathrm{a}, \mathrm{b})$ offer an interesting test-bed for the argumentmodifier distinction in NPs, in English and Russian and cross-linguistically.
a. English:
John's teacher, Jot
John's chair, friend of John's
b. Russian: Mašin
učitel, Mašin
stul, drug Maši
Maša-POSS-M.SG. teacher, Maša-POSS-M.SG chair, friend Maša-GEN
Maša's teacher,
Maša's chair,
Maša's friend

Many, perhaps all, genitives seem to have some properties of arguments and some of modifiers, but some seem more argument-like and some more modifier-like. Recent proposals by Jensen and Vikner (1994), Vikner and Jensen (ms.1999), Partee and Borschev (1998), Borschev and Partee (1999a,b) analyze all genitives as argument-like, a conclusion we are no longer sure of for English (see Partee and Borschev, in press a). But while we now doubt that such an analysis is correct for all kinds of genitives in all languages, we believe that it is correct for some kinds of genitives in some languages. It is not easy to settle the question of whether there is a substantive difference between these two "roles" of genitives, and it may well be the case that all or many genitives play both roles at once.

In both English and Russian there are several constructions which may in some (possibly metaphorical) sense express "possession"; and in each language there seem to be several different kinds of meanings for constructions involving the "genitive" (genitive morphology in Russian, the morpheme 's in English). The correlation between constructions and meanings is not transparent.

One central question about genitive constructions, then, is the following: Are all, some, or no genitives arguments of nouns, and if so, which ones (and how can we tell?), and of what kind, and at what 'level' of analysis? Are some genitives able to get argument-like interpretations without actually being arguments in any structural sense?

In this paper we examine semantic aspects of the question of whether all genitives can and should be given a unified analysis, or whether we can find a satisfying way of accommodating a two-structures analysis, remaining as neutral as possible throughout on the syntactic aspects of the question.

\section{Genitives and related constructions: the challenge}

The terminology surrounding "possessives" and "genitives" is confusing, since the correspondences among morphological forms, syntactic positions, grammatical relations, and semantic interpretations are complex and debated, and vary considerably across languages. For clarification, let us distinguish at least the following: ${ }^{3}$

(3) a. Possessive pronouns: E. my, his; R. moj 'my', ego 'his'; E. predicative forms mine, his and postnominal forms of mine, of his.

b. English "Saxon genitives": John's, and the postnominal Saxon genitive of John's.

c. English PP with of + Acc.

d. Russian postnominal genitive NP: Mendeleeva 'of Mendeleev', tigra 'of a/the tiger'

e. Russian prenominal possessive: Mašin dom 'Masha's house'.

\footnotetext{
2 As noted in the next section, there is no perfect term to cover the whole range of "genitive" and "possessive" constructions. We use "genitive" as our neutral cover term, reserving "possessive" for notional possessives.

3 We use English and Russian for illustrative purposes, abbreviated below as E and R.
} 
Some of the problems of the semantics of genitives affect all of these, while some of the problems require making distinctions. Very similar problems arise in corresponding constructions in many other languages, and related problems arise with the English verb have and its lexical and constructional counterparts in other languages (Bach 1967, Freeze 1992, Landman and Partee 1984, Szabolcsi 1994, Jensen and Vikner 1996, Partee 1999b). The present work concerns the possible need for a distinction between genitives as modifiers and genitives as arguments, and the role that predicate possessives may play in resolving that issue. We leave out of discussion the most clearly modifier-like genitives that occur in compounds like $a$ boys' $c l u b$, although Munn 1995 has shown that the line between those and other genitives is not as sharp as had been thought.

One starting point is the following data from Partee (1983/97: 464):

(4) a. John's team

b. A team of John's

c. That team is John's

(5) a. John's brother

b. A brother of John's

c. (\#) That brother is John's

(6) a. John's favorite movie

b. A favorite movie of John's

c. (\#) That favorite movie is John's

Informally, a unified interpretation of genitive phrase "Johns" that applies to all of these cases is that the genitive phrase always expresses one argument of a relation, for which we will use the descriptive term "genitive relation", following Jensen \& Vikner (1994). But the relation can come from any of three sources: (i) the context, as in (4) ("plays for" "owns", "is a fan of", etc.); this happens when the noun is a plain 1-place predicate; (ii) an inherently relational noun like "brother"; (iii) an inherently relational adjective like favorite.

Following Partee (1983/97), we call case (i) the "free $\boldsymbol{R}$ " reading, and cases (ii) and (iii) “inherent $\boldsymbol{R}$ ” readings.

The puzzles include these: can (and should) examples (4a) and (5a) be given a uniform analysis, and if so, how? Or does the genitive construction combine differently with plain and relational nouns, and if so, are these differences predictable from some general principles? Should the first case be split into two distinct cases, one being a default preference of the "genitive" construction itself for a genitive relation in the family of "owns", "possesses", "controls", possibly with a distinct syntactic source from the context-dependent "free $\boldsymbol{R}$ " readings? And does the analysis of genitives require that phrasal as well as lexical categories be able to take complements? The examples in (6) show that argument-like genitives cannot always simply be analyzed as complements of a lexical noun, since it is the whole N-bar favorite movie that provides the relation of which John is an argument ${ }^{4}$.

\footnotetext{
4 We are grateful to Marcel den Dikken for suggesting that one should explore a possible approach on which the genitive in (6) is a complement of the lexical adjective favorite, so that genitives, when complements, would always be complements of some lexical item. That could certainly be made to work semantically, as long as the adjective favorite is always a function applying to the noun's meaning. As den Dikken notes, "it does complicate the syntax at first blush"; we suspect that a fuller investigation might best be carried out in connection with a study of the interaction of genitives with superlative and superlative-like constructions as in John's best picture, John's first picture.
} 
The Russian "genitive modifier" (GM) construction exemplified in (7) presents similar challenges, showing a similarly diverse range of "genitive relations", with a similar range of relational and non-relational nouns, although there are interesting differences between English and Russian to account for as well.
a. ljubitel' košek
lover-NOM.SG cat-GEN.PL
'lover of cats, cat-lover'
b. rost čeloveka
height-NOM.SG man-GEN.SG
'height of the/a man'
c. nožka stola
leg-NOM.SG table-GEN.SG
'leg of the table, table leg'
d. krug syra
circle-NOM.SG cheese-GEN.SG
'circle (wheel) of cheese'
e. stakan moloka
glass-NOM.SG milk-GEN.SG
'glass of milk'
f. portret Peti
portrait-NOM.SG Petja-GEN
'picture of Petja'
g. sled tigra
track-NOM.SG tiger-GEN.SG
'track of the/a tiger'
h. sobaka dočeri
dog-NOM.SG daughter-GEN.SG
'the daughter's dog'
i. nebo Andreja Bolkonskogo
sky-NOM.SG Andrej-GEN Bolkonsky-GEN
'Andrej Bolkonsky's sky'

In the case of Russian, the question of whether the examples in (7) are all instances of a single construction is even more difficult than in the case of English, since the uses of the Russian genitive NP cover uses analogous to both the English Saxon genitive in (4-6) and English PPs with of + Acc.

At a descriptive level, virtually all authors who have grappled with the semantics of genitive constructions are in agreement that in some cases the genitive NP seems argument-like and in other cases it seems modifier-like. The "argument" nature of at least some genitives is clearest in the case of some deverbal nouns, those called "Complex Event Nominals" by Grimshaw (1990) and Schoorlemmer (1995), "Derived Nominals" by Babby (1997), and "process nominals" by Rappaport (1998).

To be slightly more precise about our relatively neutral assumed syntax for the first of these constructions, and for the Russian postnominal genitive construction, we represent the syntactic structure as in (8) below, a linearized form of the schematic phrase structure tree of Borschev and Partee (1999b):

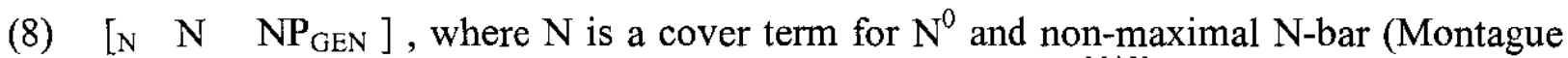
1973 's CN and CNP), and NP is a cover term for both $\mathrm{N}^{\mathrm{MAX}}$ and DP. 
The semantic question is: do the genitive constructions [ $\left[\begin{array}{lll}\mathrm{N} & \mathrm{N} & \mathrm{NP}_{\mathrm{GEN}}\end{array}\right]$ have a uniform compositional interpretation?

\section{Uniform approaches and 'splitting' approaches}

As we will illustrate in Section 4, given the possibilities that have been raised by work on type-shifting in the past decade or so, it seems that the semantics of any simple "NP's N" or

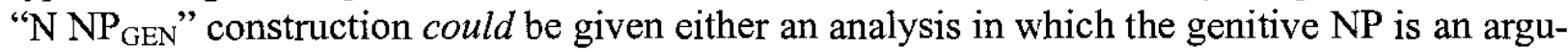
ment or one in which it is a modifier. In this paper we are not trying to settle all the relevant arguments for even one such construction, but rather to explore the available alternatives from a semantic point of view. A full analysis of any genitive construction in any language requires greater syntactic specificity than we are providing here, as well as a theory of the interaction among lexical, structural, and contextual factors, and relevant evidence may be of many kinds, including binding and extraction facts, behavior in coordinate constructions, iterability, word order constraints, quantificational properties, and other properties. There are many proposals for many such constructions in many languages in the literature by now, in a variety of theoretical frameworks, and we are not prepared to enter the sometimes crucial syntactic debates that are involved in some of the competing analyses. But with little more than the minimal syntactic assumptions noted above, we can address some of the central issues of semantics and compositionality.

For concreteness, let us discuss approaches to the semantics of the English genitive construction illustrated by the phrase book of John' $s^{5}$.

There are in principle three possibilities, a splitting approach and two kinds of uniform approaches.

(i) One possibility is to split the construction into two different genitive constructions, treating "inherent $\boldsymbol{R}$ " genitives (brother of John's) as type-raised arguments and "free $\boldsymbol{R}$ " genitives (team of John's) as (intersective) modifiers (Partee 1983/97, Barker 1995). This approach starts from the intuition that some genitives are arguments and some are modifiers. We illustrate it in Section 4 below. If no uniform approach can be made to work (for a given genitive construction in a given language), a splitting approach may be necessary. One of our main points here will be, however, that raw intuitions of ambiguity or of 'argumenthood vs. modifierhood' are not real evidence ${ }^{6}$. Most linguists would tend to prefer a uniform analysis if it can be made to work, but as Dowty $(1997 ; 2000)$ argues, that is not an uncontroversial attitude. In the subsequent sections of this paper, we explore empirical arguments for and against the ambiguity of various genitive constructions.

(ii) One possibility of a uniform approach is to assimilate all cases to the "inherent $\boldsymbol{R}$ " reading, treating all genitives as arguments, or as type-lifted arguments. This option was introduced by Jensen and Vikner (1994), and further explored in Partee and Borschev (1998), Borschev and Partee (1999a,b), and Vikner and Jensen (ms. 1999). We describe this approach

\footnotetext{
5 There is already a problem in using this construction for illustration, since a number of authors, including Barker (1995), have argued that the English postposed genitive is a reduced partitive, book of John's books, and that there is therefore no simple construction of the form $\left[\mathrm{N} N \mathrm{NP}_{\mathrm{GEN}}\right]$ in English. The reason we are not using the construction John's book for our 'basic' case is that the preposed genitive in English seems to combine the "basic" genitive with an implicit definite article. We are assuming here that the postposed genitive is a basic construction in English (see also Lyons 1986), but the general points we make would also hold for the preposed genitive "minus the meaning of the definite article". Thanks to Michael Brody (p.c.) for noting that one should of course explore the "underlying position" of the preposed genitive, which may move into a determiner position from somewhere else, at least in theories with syntactic movement.

6 This point is made more systematically for a wide range of constructions in Dowty (2000).
} 
in Section 4 below, and show some empirical advantages of this approach over a splitting approach. In Section 5 we review arguments from Partee and Borschev (in press a) to the effect that in spite of these attractions, this uniform approach seems not to be correct for all genitive constructions in all languages, although it may well be correct for some. These conclusions open up interesting typological questions and invite the task of finding more kinds of evidence for 'true arguments' of nouns.

(iii) Another possibility of a uniform approach is to assimilate all cases to the "free $\boldsymbol{R}^{\text {" }}$ reading. A variant of that option was proposed by Hellan (1980). Partee (1983/97) argued against it on the basis of the contrast among the (c) examples in (4-6), but we will return to it in Section 6. On this kind of analysis, all genitives are basically modifiers. Within approaches to modifier genitives, recent work by Kolliakou (1999) shows the need for a further distinction between genitives as predicates of type $<e, t>$, i.e. as intersective modifiers, and genitives as possibly non-intersective intensional modifiers of type $<<e, t>,<e, t>>$. As we will discuss in Section 6, some of the principal challenges to treating all genitives as modifiers include the obligatoriness or near-obligatoriness of a genitive "complement" with some relational nouns, and the apparent systematicity of argument-inheritance with some kinds of deverbal nouns. For the treatment of genitives as intersective modifiers, another problem is the apparent impossibility of some genitives in predicate position, as illustrated in the contrasts in (4-6) above.

\section{Two theories of genitives}

Partee (1983/97) proposed two distinct genitive constructions with relational and non-relational nouns, the latter incorporating a "free relation variable $\boldsymbol{R}$ " whose value must be supplied by context. On the other hand, (a modified version of) Jensen and Vikner (1994) offers a uniform interpretation of the genitive, with coerced type-shifting of the N-bar to a relational reading when necessary. The investigation of the differences between these two approaches, in part through an ongoing dialogue which Borschev and Partee have been carrying on with Jensen and Vikner over the past two years, has led us to an appreciation that the problem of the semantics of the genitive construction(s) is a much richer domain of inquiry than we had originally imagined, and to convergence on some issues and new questions on others.

A note about notation: in what follows we use CN for a ("plain") N-bar of type <e,t> (one-place predicate, with only a "referential" $\theta$-role (Williams 1981; the $\mathrm{R}$ role of Babby 1997)), and TCN for a ("transitive" or "relational") N-bar of type <e, <e,t>> like father, favorite movie.

The analysis of Partee (1983/97) posits an ambiguity in the construction, with the N-bar supplying the relation if it is relational, and with the construction supplying a "free relation variable" if the N-bar is not relational. We illustrate the postnominal genitive, as in (4b), (5b), (6b), which Partee (1983/97) analyzed as a modifier, treating the prenominal genitive in (4a), (5a), (6a) as a composition of the postnominal genitive with an implicit definite determiner.

Postnominal genitive (of John's): combines with $C N$ or TCN to make a CN.

When a genitive NP combines with a plain $\mathrm{CN}$, type $<\mathrm{e}, \mathrm{t}\rangle$ : the construction provides a "free $\boldsymbol{R}^{\prime \prime}$, a variable of type $<\mathrm{e},<\mathrm{e}, \mathrm{t}>>$ which we write as $\boldsymbol{R}_{\boldsymbol{i}}{ }^{7}$

As with the use of free variables like $x_{i}$ to represent pronouns used without linguistic antecedent, we assume as a felicity condition on the use of free $\boldsymbol{R}_{i}$ that the context should make it sufficiently clear to the hearer what particular relation the speaker has in mind. 


$$
\begin{array}{ll}
\text { of John's: } & \lambda \boldsymbol{P} \lambda \boldsymbol{x}\left[\boldsymbol{P}(\boldsymbol{x}) \& \boldsymbol{R}_{i}(\mathrm{John})(\boldsymbol{x})\right] \\
\text { team of John's: } & \lambda x\left[\operatorname{team}(\boldsymbol{x}) \& \boldsymbol{R}_{i}(\mathrm{John})(\boldsymbol{x})\right]
\end{array}
$$

When a genitive NP combines with a TCN, type $\langle\mathrm{e},\langle\mathrm{e}, \mathrm{t}\rangle\rangle$, the TCN provides its "inherent $\boldsymbol{R}^{\prime \prime}$.

(10) of John's:

$$
\begin{array}{ll}
\text { of John 's: } & \lambda \boldsymbol{R}[\lambda x[\boldsymbol{R}(\mathbf{J o h n})(x)]] \text { or equivalently, } \lambda \boldsymbol{R}[\boldsymbol{R}(\mathrm{John})] \\
\text { teacher of John's: } & \lambda x[\operatorname{teacher}(\mathrm{John})(x)]]
\end{array}
$$

Jensen and Vikner (1994) propose that an analysis which incorporates coerced type-shifting in the sense of Partee (1987) should be able to do without two separate rules for the genitive. They present an alternative analysis, building on the framework of Pustejovsky $(1993,1995)$ : the genitive must always combine with a relational common noun (phrase), coercing a oneplace predicate noun to a two-place relational meaning ("team" to an appropriate sense of "team-of"). Their analysis corresponds to the "inherent $\boldsymbol{R}$ " case of Partee (1983/97), and with a relational noun like teacher the two analyses agree. The difference arises with a plain oneplace $\mathrm{CN}$ like chair or team, which on their analysis is coerced to a TCN interpretation. Jensen and Vikner follow Pustejovsky in appealing to the qualia structure of the lexical entry to guide the coercion, so that for instance the telic role of chair ("chairs are to sit in") licenses the shift of $\mathrm{CN}$ chair to TCN chair illustrated below.

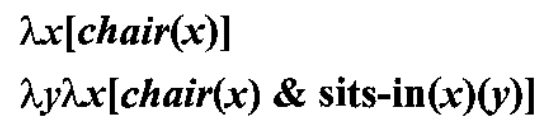

Initially we had some important differences with Jensen and Vikner concerning the degree to which lexical meaning drives coercion. In Vikner and Jensen (ms. 1999) and Partee and Borschev (1998), there is agreement that on the most general version of their approach, the genitive construction should always demand a TCN to combine with, and if it finds instead a CN it will coerce it by whatever means are available and "natural", sometimes lexical, sometimes pragmatic. (We make a less sharp distinction between lexically and contextually supplied shifted meanings than Jensen and Vikner do, because of the outlook on the integration of information from lexical and other sources described in Partee and Borschev 1998, Borschev and Partee 1998.) A "pragmatic" coercion is seen as shifting the noun to a relational reading that incorporates the "free relation variable" of Partee (1983/97) into the shifted noun meaning.

\section{(12) TCN team:}

\section{$\lambda y \lambda x\left[\operatorname{team}(x) \& R_{i}(x)(y)\right]$}

As in Partee's analysis, a felicitous use of an expression with a free variable requires that the context make a particular choice of value for the variable salient. Partee and Borschev (1998, in press b), Borschev and Partee (1999a) propose extensions to Jensen and Vikner's coercion approach to cover also the "contextual" cases, and point to a need for more fine-grained coercion principles to cover phenomena involving the relational adjective favorite and the difference in "most likely relation" in the interpretation of examples like John's movie and John's favorite movie.

One main difference between the two approaches is then in where a "free relation variable" is added in a case where context is driving a pragmatically based coercion. Let's suppose that team of Mary's is such a case. 
(13) Jensen and Vikner:
of Mary's:
$\lambda \boldsymbol{R}[\lambda \boldsymbol{x}[\boldsymbol{R}(\operatorname{Mary})(x)]]$
(shifted) team:
$\lambda y\left[\lambda x\left[\operatorname{team}(x) \& R_{i}(y)(x)\right]\right]$
team of Mary's:
$\left.\lambda x\left[\operatorname{team}(x) \& R_{i}(\operatorname{Mary})(x)\right]\right]$

(14) Partee (1983):

$$
\begin{array}{ll}
\text { of Mary's: } & \lambda \boldsymbol{P} \lambda \boldsymbol{x}\left[\boldsymbol{P}(\boldsymbol{x}) \& \boldsymbol{R}_{\boldsymbol{i}}(\operatorname{Mary})(\boldsymbol{x})\right] \\
\text { (non-shifted) team: } & \operatorname{team} \\
\text { team of Mary's: } & \left.\lambda \boldsymbol{x}\left[\operatorname{team}(\boldsymbol{x}) \& \boldsymbol{R}_{i}(\operatorname{Mary})(\boldsymbol{x})\right]\right]
\end{array}
$$

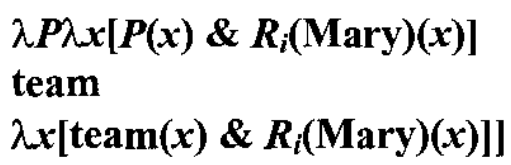

The final result is the same; but for Jensen and Vikner the free relation variable comes in as part of the meaning of the shifted noun, while for Partee (1983/97) it comes in as part of the meaning of the genitive construction itself. Does this difference in "where" the free relation variable is situated ever make a detectable difference? Yes.

Partee and Borschev (1998) give an empirical argument in favor of Jensen and Vikner's approach, based on an analysis of the example Mary's former mansion, suggested to us by Norvin Richards (p.c.). The argument rests on four assumptions, as spelled out in (15) below.

(15) Assumptions:

(i) mansion is lexically a 1-place noun.

(ii) former is an endocentric modifier, lexically a CN/CN, shiftable to a TCN/TCN. former as $\mathrm{CN} / \mathrm{CN}$ : former monastery, former dancer. former as TCN/TCN: former owner, former friend.

(iii) The "free relation" variable in this case has as one of its most salient values something like "owns" or "lives in".

(iv) Mary's former mansion has two readings: "Reading A": a former mansion (perhaps now just a ruin) that is (now) Mary's. I.e., now Mary's, formerly a mansion; and "Reading B": something that was formerly Mary's mansion; it may still be a mansion, but it's no longer Mary's.

On the Partee (1983/97) account, there is no motivation for any type-shifting to occur, and the "free relation" "owns" will be introduced with the genitive Mary's, after former has combined with mansion. This means that the free relation ("owns") in the interpretation of the genitive Mary's will never be under the scope of former. As a result, Partee (1983/97) can derive Reading A above, but not Reading B. Tree (16) shows the compositional structure of Mary's former mansion on the account of Partee (1983/97).

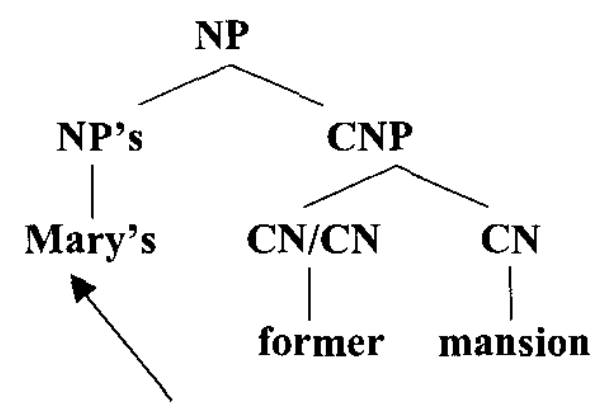

free $\boldsymbol{R}$ introduced here

But Jensen and Vikner's account, with coercion of $\mathrm{CN}$ to TCN, does provide derivations for both readings, which Partee's account cannot. For Jensen and Vikner, Mary's coerces former 
mansion to a relational TCN. Given our assumptions, there are two ways that former mansion could shift to a TCN.

(i) Initially leave mansion as a $\mathrm{CN}$, treat former as $\mathrm{CN} / \mathrm{CN}$, combine them to form a $\mathrm{CN}$, as on Partee account; then shift that $\mathrm{CN}$ to a TCN, bringing in the free variable at that stage to get the shifted meaning of former mansion shown below in (17):

\section{$\lambda y\left[\lambda x\left[\right.\right.$ former(mansion) $\left.\left.(x) \& R_{i}(y)(x)\right]\right]\left[R_{i}:\right.$ "is owned by"]}

This corresponds to Reading A above, with the free $\boldsymbol{R}$ introduced at the point where the CNP shifts to become a TCNP. The compositional structure would be almost identical to that in tree (16), differing only in "where" the free $\boldsymbol{R}$ is introduced.

(ii) Or shift mansion to a TCN, and former to a TCN/TCN, combine them to form a TCN as shown below in (18):

(18) $\lambda y[\lambda x[$ former(mansion-of $)(x)(y)]]$, where mansion-of is an abbreviation for $\lambda y\left[\lambda x\left[\operatorname{mansion}(x) \& R_{i}(y)(x)\right]\right]$

This corresponds to Reading B above, with compositional structure as in (19) below.

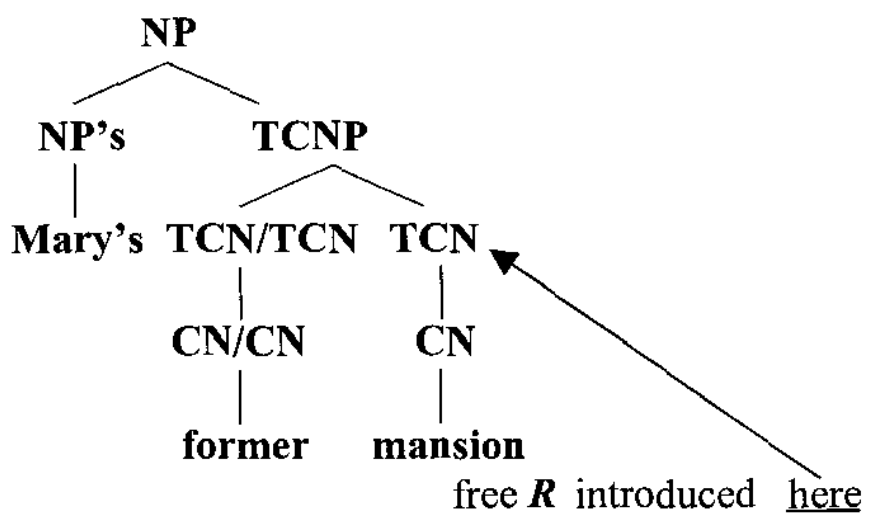

We assume that both of these ways of coercing the phrase former mansion are structurally available; different choices of lexical items or different contexts may favor one over the other, but since both are consistent with all the principles that we are aware of, the Jensen and Vikner approach successfully predicts the ambiguity and therefore has a clear empirical advantage over the Partee (1983/97) approach $^{8}$.

\section{Problems for the "argument-only" unified approach}

In spite of the theoretical appeal of the "one genitive" approach and its ability to solve the problem of Mary's former mansion, we are still not convinced that it is correct for English. Interestingly, the arguments against a uniform analysis for English genitives do not apply to Russian genitives. Russian seems to show a clearer split between a genitive construction which does indeed seem to be uniformly argumental and a prenominal possessive which is more modifier-like.

One of our main worries, discussed in Partee and Borschev (in press a), concerns predicate genitives, and our earlier observation that predicate genitives seem to favor "free $\boldsymbol{R}$ "

\footnotetext{
8 An alternative analysis of the ambiguity, based on different assumptions which we do not share, has since been offered by Larson and Cho (1999). As noted by Marcel Den Dikken (p.c.), one non-standard assumption we are making is that phrasal categories (like TCNP) can take argument; this is a standard assumption in categorial grammar but not in most other frameworks.
} 
interpretations, together with the fact that predicate genitives are not in a structural argument position unless one posits an empty head noun accompanying all predicate genitives.

As we examine predicate genitives and contrast them with the better candidates for 'argument genitives', it will emerge that the semantics of the most clearly predicate genitives seems to center on the notion of possession; so the key distinction may not after all be "free $\boldsymbol{R}$ " vs. "inherent $\boldsymbol{R}$ ", but rather a distinction between "possessive" modifiers and genitive arguments. We address this issue further in Sections 6 and 7.

\subsection{Predicate genitives: a problem for the "one genitive" approach?}

If some genitives can occur as basic $<e, t>$ predicates, that would suggest that when those same genitives occur inside the NP, they are basically modifiers, and not arguments, returning us to the distinction posited in the earlier Partee (1983/1997) approach.

If there are no genitives that demand a treatment as basic type $<\mathrm{e}, \mathrm{t}>$ predicates, that would be an argument in favor of treating all 'modifier genitives' occurring inside an NP within the "one genitive" approach of Jensen and Vikner.

But if we find in some languages that there are systematic differences in form and/or interpretation between certain genitives that occur only NP-internally and others that occur both predicatively and NP-internally, that would present a serious challenge to the "one genitive" approach, at least for those languages.

But the issue is empirically complex for at least two reasons:

(i) there may be independent reasons (syntactic or morphological) why some kinds of genitives (e.g. Russian genitives) cannot occur as predicates;

(ii) and some predicate genitives may be elliptical full NPs; it is not always easy to tell. Much of what follows is concerned with this problem.

In the following sections, we look at evidence about predicate genitives in English, Russian, German, and Polish. The evidence supports the idea of two semantically different kinds of genitives, with some forms, such as English Saxon genitives, used for both.

One kind are argument genitives, which fit the Jensen and Vikner analysis; these occur in construction with a relationally interpreted noun (or with an adjective like favorite plus a noun). Argument genitives do not occur in type $\langle e, t>$, so when they occur alone, they are interpreted as elliptical NPs with a relational noun implicitly understood. The Russian genitive appears to be of this type, and we consider the Jensen and Vikner analysis correct for the Russian genitive construction.

The other kind are true predicative genitives, basically of type $<e, t>$, interpreted approximately as in the corresponding analysis of Partee (1983/97), but with the "free $\boldsymbol{R}$ " preferentially interpreted as some kind of "possession" or "control". To represent the way this distinction differs from the original distinction of Partee (1983/97), we will stop referring to

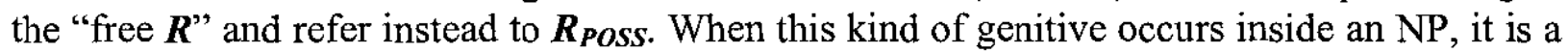
modifier rather than an argument. We believe that the Russian prenominal genitive forms discussed in Section 5.1.2 are of this type.

Since the English Saxon genitives, as well as genitive pronouns in all four of the languages looked at here, have both uses, we conclude that the "one genitive" approach cannot be correct for those constructions.

But we are left with a puzzle concerning the large proportion of cases which could seemingly be analyzed either way: are they all "ambiguous"? We will return to this puzzle, which remains open, in Section 7.

\subsubsection{Predicate genitives in English}

The nature of predicate genitives is less clear in English than in some other languages. It is difficult to be sure whether an apparent predicate genitive like John's in (4c), repeated below, 
is a simple one-place predicate with an $\boldsymbol{R}_{P O S S}$ or "possession" reading, or is an 'argument genitive' occurring as part of an elliptical NP, i.e. with John's implicitly in construction with another occurrence of team.

(4c) That team is John's.

But:

(20) a. *That father is John's.

b. *That favorite movie is John's.

c. That teacher is John's.

d. His [pointing] father is also John's.

e. Dad's favorite movie is also mine.

f. *That father is John's father.

The good examples in (20), namely $(20 \mathrm{c}, \mathrm{d}, \mathrm{e})$, all have predicate genitives that may be interpreted as elliptical NPs': John's teacher, John's father, my favorite movie. The bad examples $(20 \mathrm{a}, \mathrm{b}, \mathrm{f})$ all have intrinsically relational head nouns (or common noun phrase in the case of $20 \mathrm{~b}$ ) that have to be interpreted non-relationally in the subject but relationally in the predicate, assuming that $(20 \mathrm{a}, \mathrm{b})$ have elliptical predicate genitives. The head noun in the subject in examples $(20 \mathrm{a}, \mathrm{b}, \mathrm{f})$ must shift to a non-relational reading in order to be compatible with the demonstrative determiner that.

It may be that there is a restriction (perhaps a processing restriction) on shifting an expression "away from" its basic meaning and then "back again" (The "bad" sentences are probably indeed not 'ungrammatical', but are nearly impossible with respect to the intended readings 'John's father', etc..) In the good examples (20d,e) we have the relational readings of the head noun (phrases) in both the subject and the (elliptical) predicate.

The relevant difference between the good (20c) and the bad (20a) may be that unlike father, teacher is lexically supplied with equally salient and closely related relational and nonrelational readings, so that one wouldn't have to 'suppress' the relational reading by shifting in order to interpret teacher in the subject NP non-relationally.

The data above, reinforced by the Dutch data mentioned in footnote 9 , strongly suggest that predicate genitives may sometimes be "elliptical" NPs or "Determiner-only" NPs. And if all bare genitives in all languages could be interpreted as elliptical NPs, then predicate genitives would not pose a problem for the "one-genitive" analysis; the difference between genitive or genitive forms that can and that cannot occur "bare" as predicates would simply reflect constraints on NP ellipsis.

9 We thank Ash Asudeh (p.c.) for example (20c), and Ekaterina Rakhilina and Elena Paducheva for examples (20d,e). We are also grateful to Per Anker Jensen for similar examples, and to all of them for helpful discussion of the possible differences between the good and bad examples.

We thank M. den Dikken for pointing out that in Dutch, the predicate possessive in example (20c) is even more clearly an elliptical NP than in English, and that Dutch furthermore is a language which clearly distinguishes elliptical from non-elliptical predicate possessives. In Dutch, in the rendition of $(20 \mathrm{c})$, the d-word die, signalling the presence of nominal structure, is obligatory, as shown in (i).

(i) Die docent is *(die) van Jan.

That teacher is *(that) of Jan

'That teacher is Jan's.'

By contrast, in (ii) both options are possible.

(ii) Die auto is (die) van Jan.

That car is (that) of Jan

'That car is Jan's.' 
But we believe that not all predicate genitives are elliptical.

We do not have conclusive arguments for English; there are several complicating factors, including problems in the analysis of copular sentences (Williams (1983), Partee (1986), Moro (1997), Heycock and Kroch (1998,1999), Partee (1999a).) So rather than try to support our intuitions about the English examples, we turn to some languages where we have found some syntactic and/or morphological distinctions that provide evidence for a distinction between modifier genitives and argument genitives ${ }^{10}$.

\subsubsection{Russian prenominal genitives vs. genitives}

In Russian, genitive pronouns and the normally prenominal quasi-adjectival possessive forms can occur in predicate position but genitive NPs cannot ${ }^{11}$. This suggests that Russian genitive NPs may always be argument-like, and that the Jensen \& Vikner uniform analysis with coercion of CNs to TCNs (extended to Russian in Borschev and Partee 1999a,b) is correct for the Russian genitive construction. It also suggests that the Russian prenominal possessive forms, and possessive pronouns (see 5.1.4), are at least sometimes modifier-like.

The Russian prenominal possessive construction studied by Koptjevskaja-Tamm and Šmelev (1994) and by Babyonyshev (1997) is illustrated in (21) and the genitive construction in (22).

a. Petin stul

Petja-POSS-M.SG. chair-M.SG.

'Petja's chair.'

b. Mamin portret

Mama-POSS-M.SG. portrait-M.SG.

'Mama's portrait.'

(22)
a. stul Peti
chair-M.SG. Petja-GEN.SG.
'Petja's chair.'
b. portret mamy
portrait-M.SG. Mama-GEN.SG.
'Mama's portrait.'

In these examples, both constructions can be used in describing the same range of cases; the possible relations of Petja to the chair or of Mama to the portrait are as various as with the English prenominal genitive. But the meanings do not "feel" identical. In the possessive construction in (21), we would like to claim (as did Schoorlemmer 1995) that the possessive Petin, mamin acts as a modifier of the head noun. We believe that the prototypical interpretation of the possessive modifier is indeed 'possession' (of the object denoted by the head noun, by the (animate) entity denoted by the noun in the possessive form.) To maintain such a claim, it seems that 'possession' must be understood in a broadly extended sense to apply to a diverse range of relations; see Heine (1997). Thus in example (21b), possession may be possession proper, 'authorship', or the relation of 'being portrayed'. But the possibility of expanding the sense of 'possession' is evidently not unlimited. Thus 'murderer of Petja' can be expressed in Russian by (23a) but not by (23b).

10 The material in this section of the paper is drawn in large part from Partee and Borschev (in press a).

1 Caveats must be put on the statement that genitive NPs cannot occur in predicate position in Russian; but the conditions under which they can occur are relatively special. 

a. ubijca
Peti
murderer-M.SG. Petja-GEN.SG.
'Petja's murderer' (murderer of Petja)
b. Petin ubijca
Petja-POSS-M.SG. murderer-M.SG.
\# 'Petja's murderer' [ok only as e.g. 'a murderer Petja has hired']

In the genitive construction in (22a), we analyze Peti as an argument of the relation which connects it to stul. In the given case, the most salient relation could alternatively be seen as some kind of possession as well; but 'possession proper' is not the prototypical interpretation for the genitive construction. The range of possible relations expressed with a genitive is extremely broad (cf. Knorina 1985, 1988, 1990, 1996, Borschev and Knorina 1990, Partee and Borschev 1998, Borschev and Partee 1999a,b).

While this data is not completely conclusive, it supports the hypothesis that the Russian genitive construction is correctly analyzed as uniformly argumental, i.e. that Jensen and Vikner's approach to English genitives is correct instead for Russian genitives. And we believe that the Russian prenominal "adjectival" possessives are basically modifiers, with the "free" $\boldsymbol{R}_{\text {Poss }}$ as the core of thcir meanings (see the analysis in (33) below). But the high overlap in possible interpretation of the two constructions, as illustrated in (21) and (22), is a puzzle.

\subsubsection{German possessive pronouns}

Tony Kroch (p.c.) suggested looking for languages that would give evidence from agreement behavior as to whether predicate genitives are more like simple (adjectival) predicates or more like full NPs. Sten Vikner (p.c) observed that German is a language that gives some evidence: Predicate adjectives in German do not agree with subjects, but predicate possessives do, suggesting that predicate possessives are indeed more like elliptical NPs than like simple $<\mathrm{e}, \mathrm{t}>$ predicates $^{12}$.

\section{Diese Bücher sind alt/*alte.}

These-N.PL books- N.PL are old $/ *^{*}$ old- PL

\section{Diese Bücher sind meine/*?mein. \\ These-N.PL books are mine- PL/*mine}

This would suggest that the "one genitive" approach may be correct for German, if all apparent predicate possessives give morphological evidence of being elliptical NPs.

But it was further observed by Hans Kamp (p.c.) and others that actually, the nonagreeing form can sometimes be used. It is used only in "standard" German, not in colloquial German, and it has an "archaic" flavor. Most interestingly, it seems that there are semantic differences between the agreeing and the non-agreeing predicate possessive, and if these data stand up, it is extremely interesting.

12 Further evidence that these predicate possessives are elliptical NPs was provided by Sigrid Beck and Irene Heim (p.c.): the possessive pronoun in (25) can be followed by adjectives (i.e. there can be ellipsis of just the head noun), while the adjective in (24) and the adjective-like possessive pronoun in (26b) cannot be. Thanks to Claudia Maienborn for correcting the mistakes in our earlier rendition of these examples.

(i) Diese Bücher sind meine alten.

These-n.pl. book-n.pl are my-n.pl. old-n.pl.

'These books are my old ones.'

(ii) *Diese Bücher sind teuer neu(en).

These-n.pl. book-n.pl. are expensive new

'These books are expensive new ones.' 
(26) a. Diese Bücher sind meine: can be any relation. These- N.PL books- N.PL are mine- PL

b. Diese Bücher sind mein: (archaic) "Possession" only. These- N.PL books- N.PL are mine (no agreement)

Further examples are given in (27) and (28). A newly naturalized citizen might say (27a), but (27b) suggests a conqueror is speaking. Any relation is possible in (28a), with the most likely possibility being the parent-child, but (28b) suggests a custody fight, i.e. a dispute about who is to be in 'possession' of the children.
a. Das Land ist (jetzt) meins.
The-N.SG land-N.SG is (now) mine-N.SG
b. Das Land ist jetzt mein.

The-N.SG land-N.SG is now mine

(28) a. Die Kinder sind meine.

The children are mine-PL

b. Die Kinder sind mein.

The children are mine.

In all of (26b), (27b), (28b), the form which shows absence of agreement in the way a predicate adjective would is limited in its interpretation to "possession". In other words, the form in which the possessive pronoun appears to be a simple predicate of type $<e, t>$ is interpreted in terms of a relation that appears to be associated with the genitive construction itself rather than with the semantics of any governing noun.

In contrast, the forms which appear to be elliptical NPs have a range of interpretations including possession but also including relations typical of 'argument' genitives, where the relevant relation is determined principally by the noun to which the genitive supplies an argument. Typical choices for the 'genitive relation' for the 'argument' genitive interpretations in (26a), (27a), (28a) might be authorship, citizenship, and the parent-child relation, respectively.

Of course "possession" itself can have metaphorical extensions, so the "possession" cases do not always have to be about ownership in a literal sense. But if these distinctions are correct, this is important evidence for the idea of two distinct genitives.

\subsubsection{Russian and Polish possessive pronouns}

In Russian, in the past tense, predicate nominals may be in the Instrumental case, particularly when indicating temporary relations. Babby (1973), Siegel (1976) and others have used case and other agreement behavior to argue that some predicative adjectives are elliptical NPs and others are simple APs. The following data may provide a basis for distinguishing among predicate possessive pronouns that are and are not elliptical NPs.
a. Éta
strana
byla
kogda-to moej

That-F.NOM.SG country-F.NOM.SG was-F.SG once my-F.INSTR.SG 'That country was once mine' ['possession' or citizenship]
b. Eta
strana
byla
kogda-to moej
stranoj

That-F.NOM.SG country-F.NOM.SG was-F.SG once my-F.INSTR.SG country-F.INSTR.SG 'That country was once my country' ['possession' or citizenship] 

a. Éta
strana
byla
kogda-to moja

That-F.NOM.SG country-F.NOM.SG was-F.SG once

my-F.NOM.SG

'That country was once mine' ['possession' only]
b. *Éta
strana
byla
kogda-to moja
strana
That-F.NOM.SG country-F.NOM.SG was-F.SG once
my-F.NOM.SG country-F.NOM.SG
'That country was once my country'

A full predicate nominal is impossible in the nominative in the context of (30b), and in the same context, a nominative predicate possessive pronoun can be interpreted only as a possessive, not as an 'argument' genitive (even with a seemingly 'free' relation.) Thus the predicate possessive in (30a) cannot reasonably be analyzed as an elliptical NP, but must be a simple $<e, t>$ predicate, and it is this occurrence of the predicate possessive that unambiguously denotes "possession". These data are similar to the German data, supporting the idea that there is a 'possessive' predicate of type $<e, t\rangle$ instantiated at least by some possessive pronouns in German and Russian and possibly also by some predicative "NP's" forms in English, distinct from other cases of predicate possessives which are elliptical full NPs and in which the possessive may be an argument of an implicit relational noun.

Wayles Browne (p.c.) suggested that we should get data on Polish, because in Polish NP - be - NP requires Instrumental on the predicate NP, whereas in Russian the predicate NP may or may not be Instrumental. And in Polish NP - be - Adj requires Nominative on the Adjective, whereas in Russian the predicate AP may be 1) short-form Adjective, 2) long-form Nominative Adjective, or 3) long-form Instrumental Adjective.

The corresponding Polish data are as follows ${ }^{13}$.
a. Ten
kraj
byt
kiedys' moim.

That-M.NOM.SG country-M.NOM.SG was-M.SG once my-M.INSTR.SG

'That country was once mine' ['possession' or citizenship]
b. Ten
$k r a j$
byt
kiedys' moim
krajem.

That-m.nom.sg country-m.nom.sg was-m.sg once my-m.instr.sg country-m.instr.sg

'That country was once mine' ['possession' or citizenship; citizenship preferred.]
a. Ten
kraj
byt
kiedys' mo'j.

That-M.NOM.SG country-M.NOM.SG was-M.SG once my-M.NOM.SG

'That country was once mine' ['possession' only]
b. *Ten
kraj
byt
kiedys' mo'j
kraj.

That-M.NOM.SG country-M.NOM.SG was-M.SG once my-M.NOM.SG country-M.SG 'That country was once my country' [ungrammatical]
c. Ten
kraj
to byt kiedys' mo'j
kraj.

That-M.NOM.SG country-M.NOM.SG PRT was-M.SG once my-M.NOM.SG country-M.SG 'That country was once my country' ['possession' or citizenship]

The Polish data confirm the hypothesis that when a predicate possessive pronoun allows an "argumental" reading, it is the remnant of an elliptical NP, and when it doesn't, it isn't. The

\footnotetext{
13 Thanks to Ania Łubowicz and Anita Nowak for judgments. For (31a), Anita reports no preference for one reading or the other, while for (31b) she reports a preference for the 'citizenship' reading. Both rejected (32b) as ungrammatical; Ania suggested that it should be corrected to (32c), which she finds possibly ambiguous. Both agreed that (32a) is unambiguously "possession" only, whereas (31a) allows either reading. The basic judgments given above in the text for $(31 \mathrm{a}, \mathrm{b})$ and $(32 \mathrm{a}, \mathrm{b})$ were further confirmed by Janusz Bien, Bozena Cetnarowska (and by a substantial majority of a group of 12 students of hers), Bozena Rozwadowska, Piotr Banski, and Joanna Błaszczak, to all of whom we are grateful.
} 
"possession" reading, which seems to be emerging as the clearest case of a non-argumental, or modifier, reading, can show up either in a remnant of an NP or as a bare $<e, t>$ predicate. This reinforces the idea that a genitive inside an NP can be either an argument or a modifier. But a genitive which is an $<e, t>$ predicate in a predicational construction cannot be an argument, presumably because it is not in construction with a head of which it could be the argument.

\subsubsection{Conclusions about predicate genitives}

So we are now inclined to believe that some predicate genitives really are plain $<e, t>$ predicates, and that those have just a possession/control reading, which we take to be the semantics of the $<e, t>$ genitive, as shown in (33) below. And other predicate genitives may be elliptical NPs, and their interpretation may have the full range of possibilities that would be displayed by a full NP with a prenominal genitive occurring in such a position. (Note that a full NP may itself have meanings of types $e,<e, t>$, or $\langle<e, t>, t>$, depending on both its internal makeup and the position in which it occurs, so the study of the full range of meanings of bare genitives as elliptical NPs needs more study.)

$$
\left[J_{o h n ' s}\right]_{\mathrm{PRED}}: \quad \lambda \boldsymbol{x}\left[\boldsymbol{R}_{\text {POSS }}(\operatorname{John})(\boldsymbol{x})\right] \quad \text { type: }<\mathrm{e}, \mathrm{t}>
$$

This conclusion supports the idea that in the case of argument genitives, the genitive relation comes principally from the relational noun, whereas in the case of the modifier genitive, whose prototypical interpretation is possession, the genitive relation comes from the genitive construction itself. The cases analyzed as "free $\boldsymbol{R}$ " in Partee 1983/1997 therefore should be split into two kinds. One kind should be assimilated to the $\boldsymbol{R}_{P O S S}$ of the "possessive" genitive, and the other treated as in Vikner and Jensen (ms. 1999) and Borschev and Partee (1999a,b), as incorporated into a coerced relational reading of the head noun.

\subsection{Other problems for the unified argument-only approach}

A second and related worry concerns acquisition. Children may acquire some kinds of genitives before they show clear mastery of relational nouns.

Mine! is one of the early expressions small children learn. And then it seems to mean "control" or possession, compatible with an $<\mathrm{e}, \mathrm{t}>$ reading, although we don't know how one could completely rule out the possibility that it is elliptical for something like $M y$ (mine) blanket! (i) We believe that this usage antedates any evidence of children's understanding of relational nouns like daddy, brother as relational. (ii) We are not sure whether genitive NPs like Bobby's occur at this early stage; M. Tomasello (p.c.) suggests that it is only personal pronouns that are seen in early predicative uses.

If it is indeed the case that children acquire 'possessive' genitives before they acquire relational nouns with relational type $\langle\mathrm{e},<\mathrm{e}, \mathrm{t}\rangle>$, then the uniform-genitive-as-arguments approach would have to posit later reanalysis, while a two-kinds-of-genitives approach would say that that earlier form persists and the argument genitive is added later. We assume that accretion is easier than reanalysis, so that would be an argument for two kinds of genitives.

Another problem for any uniform approach, either modifier-only or argument-only, comes from the complex patterns of constraints on multiple genitives found with many genitive constructions in various languages. While the data are complex and often controversial, at least some of the data suggest that the number of argument genitives that can occur with a given noun is rarely more than one, and that when two or more genitives are able to occur with a noun, at least one of them must be a 'possessive', something that would be easiest to explain if the possessive is a modifier rather than another argument. The typical pattern of constraints suggests that a noun can have at most one genitive argument (although Babby 
(1997) and a few others have argued for two genitive argument positions in the Russian noun phrase). One would expect that a noun can have any number of modifiers, but if genitive modifiers are all of the same kind, "possessive", then a restriction to just one genitive modifier would be similar to the blocking of multiple adverbials of the same semantic function on a single verb.

\section{A possible "modifier-only" unified approach, and problems}

In this section we suggest, tentatively, a possible "modifier-only" unified approach to the English genitive and other genitives which appear to have both 'modifier' and 'argument' uses. We believe this approach preserves the insights of Jensen and Vikner's unified "inherent-R" approach. This approach is similar in some important respects to that of Hellan (1980), and appears to be subject to some of the same potential problems.

\subsection{Steps toward a uniform modifier analysis.}

Suppose we would like team of Mary's, teacher of Mary's, brother of Mary's, height of Mary('s), sky of Mary's all to look like instances of intersective modification by an <e,t> predicate $^{14}$. Then we might represent them as in (34); but then more must be said about how the formulas in (34) are to be interpreted.
a. $\lambda \mathbf{x}\left[\operatorname{team}(\mathbf{x})\right.$ and $\left.\mathbf{R}_{\mathbf{G E N}}(\operatorname{Mary})(\mathbf{x})\right]$
b. $\lambda \mathbf{x}\left[\operatorname{teacher}_{1}(\mathbf{x})\right.$ and $\left.\mathbf{R}_{\mathrm{GEN}}(\operatorname{Mary})(\mathbf{x})\right]$
c. $\lambda \mathbf{x}$ [brother $1(x)$ and $\left.R_{\text {GEN }}(\operatorname{Mary})(x)\right]$
d. $\lambda \mathbf{x}\left[\right.$ height $_{1}(\mathbf{x})$ and $\left.\mathbf{R}_{\mathrm{GEN}}(\operatorname{Mary})(\mathrm{x})\right]$
e. $\lambda \mathbf{x}\left[\operatorname{sky}(\mathbf{x})\right.$ and $\left.\mathbf{R}_{\text {GEN }}(\operatorname{Mary})(\mathbf{x})\right]$

In this case, the basic intersective meaning of (of) Mary's would be as in (35).

\section{$\lambda \mathbf{x}_{\mathrm{e}}\left[\mathbf{R}_{\mathrm{GEN}}(\operatorname{Mary})\left(\mathbf{x}_{\mathbf{e}}\right)\right]$}

And suppose we want axioms such as (36) to tell us what sorts of relations can be 'genitive relations'.

\section{(36) teacher $_{2}(\operatorname{Mary})(x) \rightarrow R_{\mathrm{GEN}}(\operatorname{Mary})(x)$}

Then we have to answer several questions. One concerns the interpretation of the one-place predicates in the representations above; another is the nature of $\mathbf{R}_{\mathbf{G E N}}$ (is it a variable or a constant?) and its place in the grammar. A third is the question of compositionality: how are such meanings derived from the meanings of the parts? Let us try to answer these questions in several steps.

Step 1: Let's reify the sortal part of the meaning of a relational noun. We can exploit the fact that every noun has a basic sortal part in its meaning. We can even define it, at least in some cases, as the projection onto the $\mathrm{x}_{\mathrm{E}}$-axis of the 'whole' meaning of the noun, where the $\mathrm{x}_{\mathrm{E}^{-}}$

\footnotetext{
${ }_{14}$ We use subscripts 1 and 2 to represent the 1-place predicate and 2-place relation versions of nouns. Thus teacher $_{1}$ is of type $\langle e, t\rangle$, while teacher ${ }_{2}$ is of type $\langle e,\langle e, t\rangle\rangle$. We discuss the meanings of 1-place versions of normally 2 -place nouns below.
} 
argument is the "external" argument, the "referential" argument. Note that this can be done whether or not the noun can ever be used as a plain sortal noun (as teacher, nose, portrait easily can be, and brother, favorite movie, edge normally cannot be), since even those for which an internal argument is obligatory still have this sortal part of their meaning. For "plain" (sortal) nouns, the sortal part of the meaning is the whole meaning.

We will refer to this definable kind of sortal meaning as the first projection of the relation denoted by the relational noun:

$$
\text { Sort }_{\text {brother }}=\lambda x \cdot \exists y\left(\operatorname{brother}_{2}(y)(x)\right)=\text { first projection of } \text { brother }_{2}
$$

Two important parameters of semantic differences among relational nouns are the following: (a) whether the noun has a "normal" independent use as a plain sortal noun, (of course in strong enough context, any noun can have a one-place use), and (b) if so, whether the sortal (one-place) variant of the noun has a meaning which amounts to more than just the first projection of the relational meaning (as teacher, lawyer does and brother does not).

Earlier examples suggested if the meaning of a relational noun's one-place variant was "nothing more than" the first projection of its relational meaning, then that noun would not normally be usable as an independent one-place predicate. But further examples make it clear that even "mere" first projections can be used independently if that property has cultural importance. In our society, being a mother or a parent is important, being a brother or an uncle is not. It is not only for nouns like teacher that sentences like (38a) are good; $(38 \mathrm{~b}, \mathrm{c})$ are also fine, but $(38 \mathrm{~d}, \mathrm{e})$ are not ${ }^{15}$.

(38) a. Many teachers voted for John.

b. Many mothers voted for John.

c. Many parents voted for John.

d. \# Many brothers voted for John.

e. \# Many uncles voted for John.

We suggest that the one-place predicates in (34) are related to the basic noun meanings as follows:

(39) a. $\lambda \mathbf{x}[\operatorname{team}(\mathbf{x})], \lambda \mathbf{x}[\mathbf{s k y}(\mathbf{x})]$ : the meanings of the plain CNs team, sky

b. $\lambda \mathbf{x}\left[\operatorname{teacher}_{1}(\mathbf{x})\right]:$ generic agentive noun, 'one who teaches'.

c. $\lambda \mathbf{x}\left[\right.$ brother $\left._{1}(\mathbf{x})\right], \lambda \mathbf{x}\left[\right.$ height $\left._{1}(\mathbf{x})\right]$ : first projections of the TCNs brother $_{2}$, height 2

The one-place predicate teacher 1 in its most basic use does not seem to be elliptical (as oneplace friend $_{1}$ usually seems to be), and is not simply the first projection of the TCN teacher, but rather the name of a profession, much like surgeon, actor.

Step 2: We need to think about how to compositionally derive the sortal part of the meaning of a phrasal NP (CNP). In simple cases it will just be the sortal part of the meaning of its head noun, but more work is needed to identify the principles which specify the effects of nonsubsective adjectives and of adjectives like favorite. Modifiers may also further specify sortal information by way of their selectional restrictions and/or their content. As a first approximation, but not an adequate general account, it is probably reasonable to assume (40).

is We mark the "bad" examples here with the symbol "\#", indicating that they are normally anomalous, but not ungrammatical. And as usual, a strong enough context can make them fully felicitous. 


\section{$\operatorname{Sort}_{C N P^{\prime}}=\lambda \boldsymbol{x} \cdot \exists \boldsymbol{y}\left(\mathrm{CNP}^{\prime}(\boldsymbol{y})(\boldsymbol{x})\right)=$ first projection of CNP'}

Step 3: In order to unify the combination of a genitive phrase with $\mathrm{CN}$ and TCN, we need to assume a natural kind of 'polymorphism', something we need for all sorts of noun-modifiers and verb-modifier. We want to be able to say that adnominal (of) Mary's can take any kind of a CNP as argument, whether 1-place or 2-place or in principle n-place. The proposal just below does not generalize to 0 -place without more work, i.e. does not immediately generalize to predicate genitives, but see below for a proposal for them. The essence of the analysis will then be as in (41-42) (using $\mathrm{N}$ as a cover variable for any lexical or phrasal $\mathrm{CN}(\mathrm{P})$ or $\mathrm{TCN}(\mathrm{P}))$ :

\section{(41) The genitive modifier (of) Mary's takes any $\mathrm{N}$-type argument, keeps the sortal part of the $\mathbf{N}$ meaning and adds a free $\mathbf{R}_{G E N}$ for the relation.}

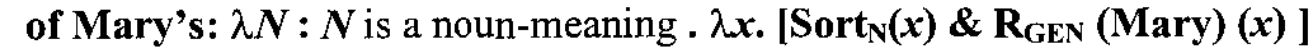

To further generalize this polymorphic operator to the 0-place case, we can follow the strategy of Montague (1970) and treat predicates as though they are modifiers of an empty noun entity. Since entity denotes a predicate true of everything in the domain, the predicative meaning given in (43) is reducible to that given in (44). This is one normal way for adjectives not originally of intersective type to shift to intersective modifiers. .

\section{$\lambda x$. [entity'(x) \& $\mathbf{R}_{\mathrm{GEN}}$ (Mary) (x)]}

\section{$\lambda x . \mathbf{R}_{\mathrm{GEN}}(\mathrm{Mary})(x)$}

For a plain $\mathrm{CN}(\mathrm{P})$, the sortal part of the meaning is simply the meaning; for a $\mathrm{TCN}(\mathrm{P})$, it is the sortal "part" of the meaning as discussed above.

Step 4: In the fourth step we are influenced by our beginning acquaintance with optimality theory and by the work of Dölling (1992, 1997), Bierwisch (1989), and Hobbs et al (1993). What we need are principles that say that if the noun already had a relational part of its meaning, then that should normally be used, and the more 'obligatorily relational' the noun is, the more strongly that inherent relation is preferred. There should be such a principle in some very general terms, something about "using all the meaning" or at least using all the "relevant" parts of the meaning.

There are also principles like those proposed by Frosch (1999) about $\mathbf{R}_{\mathbf{G E N}}$ being salient, being 'shared information', having suitable uniqueness properties. And there are principles relating to the content of the Genitive relation, explored by Jensen and Vikner (1994, 1996), Vikner and Jensen (ms. 1999), and Partee and Borschev (in press b) - $\mathbf{R}_{\mathbf{G E N}}$ likes to be agentive, it likes to be part-whole, it doesn't like to be telic in the sense of Pustejovsky 1995.

\subsection{Compositionality issues.}

If we put together the meaning of brother of Mary's on this view, what is going on? Perhaps we are moving toward a view that blends unification with ordinary function-argument application. If the meanings of brother and of Mary's are as in (45a,b), function-argument application would give (45c), and (i) an axiom analogous to that in (36) would tell us that an available value for the variable $\mathbf{R}_{\mathbf{G E N}}$ is brother $_{2}$, and (ii) there should be a general principle 
to the effect that if the sortal part of brother is not a salient property on its own, any value for $\mathbf{R}_{\mathbf{G E N}}$ other than brother 2 will yield an anomalous (or at least very hard to interpret) reading.

(45) a. brother: $\lambda \mathbf{y} \lambda \mathbf{x}\left[\right.$ brother $\left._{2}(\mathbf{y})(\mathbf{x})\right]$

b. of Mary's: $\lambda N: N$ is a noun-meaning $\cdot \lambda x$. [ $\left.\operatorname{Sort}_{\mathbf{N}}(x) \& \mathbf{R}_{\mathbf{G E N}}(\operatorname{Mary})(x)\right]$

c. brother of Mary's: $\lambda x$. [Sort $\operatorname{Srother}_{(x)} \& \mathbf{R}_{\mathrm{GEN}}$ (Mary) $\left.(x)\right]$

Note the contrast between the English of $+\mathrm{NP}_{\mathrm{ACC}}$ construction (portrait of John), which is strictly argumental, and the postnominal genitive (portrait of John's), which allows any relational reading except that expressed by portrait of John. This contrast shows that there are evidently some "Blocking" principles: the reason that portrait of John's can't usually mean what portrait of John must mean is presumably the very existence of portrait of John with its more specific meaning. There is no inherent prohibition of such a meaning, or even a dispreference for it, but it is blocked by the existence of the more specific alternative. One good argument for this approach to such examples is that there is no such effect in prenominal position (John's portrait), where there is no alternative expression.

Such blocking principles need to be explored further as a potentially important part of the explanation of the typological differences across languages in the range of relations expressed by the genitive and other constructions in connection with the existence of other "competing" constructions in the same language. For example, English genitives are not used for some of the relations expressed by genitives in Russian, apparently because of competition from the Noun-Noun compound construction in English (see the glosses of the examples in (7).)

\subsection{Predicate genitives again.}

Since the uniform meaning proposed above amounts to a type-raised "predicate-conjunction" meaning, it should be based on a simple predicative meaning (type $<\mathrm{e}, \mathrm{t}>$ ) as shown below; this is equivalent to the meaning derived by the strategy of Montague (1970) given in (43).

\section{(46) Mary's PRED $_{\text {in }} \lambda x$. $\mathbf{R}_{\text {GEN }}$ (Mary) (x)}

But at this point we should probably bear in mind the "Janus-faced" nature of the genitives that we noted in section 5: for "pure" non-elliptical predicate genitives, it may not be right to call this a "genitive" relation at all; this is where the distinction between "genitive" and "possessive" may become important.

\section{Mary's $_{\text {PRED }}: \lambda x$. RPoss $_{\text {(Mary) }(x)}$}

It is in our minds a question for further research how to argue for a distinction between two classes of potentially "free" relations; we suspect that the distinction will be one of prototypical preferences (cf. Dowty 1989) rather than an absolute one. Possibly, RPoss should just be thought of as one of the most salient relations (or family of relations) accessible when there is no salient sortal information in the construction: not only in the predicative case, but in cases like anything of mine, all this stuff of John's, where the head noun has minimal lexical content.

To say all these things, we need $\mathbf{R}_{\mathbf{G E N}}$ as a notion; the grammar (and universal grammar) has to be able to talk about it, has to be able to describe constraints and preferences. So it isn't just the bare logical notion of a two-place relation; it's a two-place relation "template" that is part of the interpretation of a particular construction. 
The approach described here, while not fully worked out, can already be seen to differ in certain crucial ways from Partee $1983 / 97$ as well as from Jensen and Vikner (1994) and Vikner and Jensen (ms. 1999) (and from Borschev and Partee 1999a,b insofar as we have been following Jensen and Vikner). We summarize the differences below:

a. Partee 1983/97: Two distinct constructions.

(i) with inherent-R nouns, Mary's is $\lambda \mathbf{R} \lambda \mathbf{x}[\mathbf{R}(\mathbf{M a r y})(\mathbf{x})]$ (a lifted argument).

(ii) with sortal nouns Mary's is $\lambda \mathbf{P} \lambda \mathbf{x}\left[\mathbf{P}(\mathbf{x}) \& \mathbf{R}_{\mathbf{G E N}}(\mathbf{M a r y})(\mathbf{x})\right]$ (a predicate lifted to become an intersective modifier.)

b. Jensen and Vikner (1994): All as lifted arguments, forcing plain nouns and NPs to shift to relational meanings. The genitive "wants" a relational TCN(P) to combine with, "wants" to give it an argument.

c. This proposal: Related in part to Hellan 1980: Assimilate all to free-R case, by (a) splitting relational nouns into a "sortal part" plus a relation, (b) making Mary's a polymorphic function, and (c) having principles which help make sure that the 'inherent R' of an inherently relational noun can't easily be ignored.

On the current proposal, all genitives could be viewed as modifiers. There are remaining conceptual problems, particularly for the "inherent $\boldsymbol{R}$ " case. The goal is to have enough general principles at work that one can simply say $\mathbf{R}_{\mathbf{G E N}}(\mathbf{M a r y})(\mathbf{x})$ and have all the rest follow.

But even if the conceptual problems can be solved, any unified approach will have to wrestle with the problem noted earlier of the limitations on the occurrence of more than one genitive with a single noun, limitations which may be better described in terms of cooccurrences of distinct genitive structures.

\section{Speculative hypotheses and prospects for a unified account}

\subsection{Two competing prototypes?}

It has often been pointed out that an "Argument" genitive is most like a direct object, an "internal argument", most intrinsic to relational nouns. A "Possessor" genitive, on the other hand, is most subject-like, agent-like, less like an internal argument, more independent; Perhaps with more work it can be shown to follow that it is hence more easily a predicate.

We started from the idea that genitives with relational nouns are basic, and have been trying to figure out what adjustments take place when a genitive is used with a plain sortal noun.

Heine (1997) starts from the other end, so to speak, with have sentences as primary concern and predicate genitives as secondary, and adnominal genitives as a tertiary interest. Inherent relations have a subordinate place in the discussion; various notions of control and 'possession' are at the forefront.

This makes us see genitives as Janus-faced. From our perspective, the deverbal nouns are in a sense archetypal relational nouns, with genitives most clearly argument-like: John's arrival, the city's destruction. From Heine's perspective the use of a have-like construction or of a genitive construction with deverbal nouns is more like the grammaticization of a metaphorical extension of possession, and inalienables like Mary's hand are closer to the core. Perhaps the child's early That's mine! is even more core-like. For genitive constructions which include the kind of possessive predicative readings discussed in section 5 , it seems clear that they are not to be treated as uniformly argument-like.

We have tried in section 6 to propose a version of the proposal of Hellan (1980) which preserves many of the properties of Jensen and Vikner's uniform argument approach within a 
uniform modifier approach. It may in the end be preferable for genitive constructions like that in English to go back to an ambiguity approach, acknowledging that genitives may arise from either of two different prototypes, though with a wide overlap in the result.

\subsection{Hypotheses and puzzles.}

We summarize below some of our specific hypotheses about particular genitive and genitivelike constructions in English and Russian.

1. The English of $+\mathrm{NP}_{\mathrm{ACC}}$ construction (portrait of John) is strictly argumental.

2. The English Saxon genitive (John's) can be used as a predicate, type <e,t $>$.

3. The English of + NP's construction (portrait of John's) is either uniformly non-argumental or ambiguously argumental/non-argumental (not sure yet). But in particular, it is not always argumental.

4. The English prenominal NP's neutralizes the distinction between postnominal of $+\mathrm{NP}_{\mathrm{ACC}}$ and of $+\mathrm{NP}$ 's. So it can be either argumental or non-argumental. [It's conceivable that 'structurally' it is never argumental, but we won't try to argue that.]

5. The Russian genitive (Maši), always postnominal, is always an argument. It can never be used as a predicate (caveats). (But it can be used with 'plain nouns' to express all kinds of relations including possession, as predicted by Jensen and Vikner's coercion analysis.)

6. The Russian prenominal possessive (Mašin, $-a$ ) can be used as a predicate, has certain limitations on its use as an argument, and is either sometimes or never structurally an argument, although it can certainly fill argument-like roles.

The puzzle that emerges is that there seem to be argumental genitive constructions and modifier 'possessive' constructions that have a very great overlap in what they can express; if this is correct, it means that we cannot use 'intuitions' of argumenthood as a good guide to whether something is 'really' an argument at a given level of structure. And Dowty (1997, 2000) has argued that the distinction between modifiers and arguments need not be inherently sharp. Fleshing out more specific proposals about the relevant structures is necessarily a theory-dependent matter and we do not intend to undertake it without the collaboration of syntacticians. There are many different proposals in the literature for different argument and nonargument positions/sources for genitives and other 'possessives' in English, Russian, and other languages.

The bottom line seems to be that type-shifting and lexical meaning shifts make many compositional routes available to very similar 'net outcomes'. The line between arguments and modifiers is not intrinsically sharp in terms of 'what is being expressed', and can only be investigated in theory-dependent ways. It will be hard to find sharp differences between a theory in which the genitive construction contributes a "possessive" relation and a theory in which the genitive construction causes the head $\mathrm{N}$ or $\mathrm{N}$-bar to shift to a relational interpretation possibly involving a "possessive" relation as one of its "preferred" relations. At this point we see more hope for a unified approach which takes all genitives as modifiers than for one which analyzes all genitives as arguments. Genitives are a domain of great semantic flexibility, where we have to find detailed language-particular evidence to try to sort out how lexical semantics, compositional semantics, and type-shifting possibilities are interacting in each particular construction. 


\section{References}

Babby, Leonard H. (1973): The Deep Structure of Adjectives and Participles in Russian. Language 49, 349-60.

- (1997): Nominalization in Russian. In: W. Browne, E. Dornisch, N. Kondrashova, and D. Zec, (eds.) Formal Approaches to Slavic Linguistics, The Cornell Meeting 1995, 54-83. Ann Arbor: Michigan Slavic Publications.

Babyonyshev, Maria (1997): The possessive construction in Russian: a crosslinguistic perspective. Journal of Slavic Linguistcs 5/2, 193-230.

Bach, Emmon (1967): Have and be in English syntax. Language 43/2, 462-485.

Baker, C. L. (1978): Introduction to Generative Transformational Syntax. Englewood Cliffs, NJ: Prentice-Hall.

Barker, Chris (1995): Possessive Descriptions. Stanford: CSLI Publications.

Bierwisch, Manfred (1989): Event nominalizations: proposals and problems. In: W. Motsch (ed.) Wortstruktur und Satzstruktur 1-73. Berlin: Akademie Verlag.

Borschev, V.B. / L.V.Knorina (1990): Tipy realij i ix jazykovoe vosprijatie (Types of entities and their perception in language). In: Language of Logic and Logic of Language, 106-134. Moscow.

Borschev, V.B. / Barbara H. Partee (1998): Formal and lexical semantics and the genitive in negated existential sentences in Russian. In: Željko Bošković, Steven Franks and William Snyder (eds.) Formal Approaches to Slavic Linguistics 6: The Connecticut Meeting 1997, 75-96. Ann Arbor: Michigan Slavic Publications.

- (1999a): Semantika genitivnoj konstrukcii: raznye podxody $\mathrm{k}$ formalizacii. (Semantics of genitive construction: different approaches to formalization.) In: Ekaterina V. Rakhilina and Yakov G. Testelets (eds.) Typology and Linguistic Theory: from Description to Explanation. For the 60th birthday of Aleksandr E. Kibrik, 159-172. Moscow: Jazyki Russkoj Kul'tury.

(1999b): Semantic Types and the Russian Genitive Modifier Construction. In: K. Dziwirek et al. (eds.) Formal Approaches to Slavic Linguistics: The Seattle Meeting 1998, Ann Arbor: Michigan Slavic Publications.

Dölling, Johannes (1992): Flexible Interpretation durch Sortenverschiebung. In: I. Zimmermann and A. Strigin (eds.) Fügungspotenzen, 23-62. Berlin: Akademie Verlag.

- (1997): Semantic form and abductive fixation of parameters. In: R. van der Sandt, R. Blutner and M. Bierwisch (eds) From Underspecification to Interpretation. Working Papers of the Institute for Logic and Linguistics, 113-138. Heidelberg: IBM Deutschland.

Dowty, David (1989): On the semantic content of the notion "thematic role". In: G. Chierchia, B. Partee and R. Turner (eds.) Properties, Types and Meanings: vol II, 69-130. Dordrecht: Kluwer.

- (1997): Adjunct-to-argument reanalysis in a dynamic theory of grammar: the problem of prepositions. Paper presented at the Blaubeuren Semantics CCG/adj-arg Conference, University of Tübingen, March 1997.

- (2000): The Dual Analysis of Adjuncts/Complements in Categorial Grammar. In: C. Fabricius-Hansen, E. Lang and C. Maienborn (eds.), Approaching the Grammar of Adjuncts. ZAS Papers in Linguistics 17, 5378.

Freeze, Ray (1992): Existentials and other locatives. Language 68, 553-595.

Frosch, Helmut (1999): German "Attributive" Genitives as Adjuncts. Paper presented at the Conference "Approaching the Grammar of Adjuncts", 22-25 Sep 1999, Oslo.

Grimshaw, Jane (1990): Argument Structure. Cambridge: MIT Press.

Heine, Bernd (1997): Possession: Cognitive Sources, Forces, and Grammaticization. Cambridge: Cambridge University Press.

Hellan, Lars (1980): Toward an Integrated Theory of Noun Phrases. Trondheim University dissertation.

Heycock, Caroline and Anthony Kroch (1998): Inversion and equation in copular sentences. In: A. Alexiadou, N. Fuhrhop, U. Kleinhenz, and P. Law (eds) ZAS Papers in Linguistics 10, 71-87. Berlin: Zentrum fuer Allgemeine Sprachwissenschaft.

- (1999): Pseudocleft connectivity: Implications for the LF interface level. Linguistic Inquiry 30, 327-364.

Hobbs, J.R., M.E. Stickel, D.E. Appelt, and P. Martin (1993): Interpretation as abduction. Artificial Intelligence $63,69-142$.

Jensen, Per Anker and Carl Vikner (1994): Lexical knowledge and the semantic analysis of Danish genitive constructions. In: S.L. Hansen and H. Wegener (eds.) Topics in Knowledge-based NLP Systems, 37-55. Copenhagen: Samfundslitteratur.

- (1996): The double nature of the verb have. In LAMBDA 21, OMNIS Workshop 23-24 Nov. 1995, 2537. Handelshøjskolen i København: Institut for Datalingvistik. 
Knorina, L.V. (1985): Ob interpretacii genitivnyx konstrukcij. (On the interpretation of genitive constructions). Theses of the workshop "Semiotic foundations of intellectual activity". Moscow: VINITI.

(1990): Narushenija sochetajemosti i raznovidnosti tropov $\mathrm{v}$ genitivnoj konstrukcii (Violations of cooccurence and varieties of tropes in genitive construction). In: Contradictions and Anomalies of Text, 115-124. Moscow.

- (1996): The range of biblical metaphors in smikhut. Moscow Linguistic Journal v.3, 80-94.

Kolliakou, Dimitra (1999): De-Phrase extractability and Individual/Property denotation. Natural Language and Linguistic Theory 17/4, 713-781.

Koptjevskaja-Tamm, Maria and Aleksej Šmelev (1994): Alešina s Mašej stat'ja (o nekotoryx svojstvax russkix "pritjažatel'nyx prilagatel'nyx"). [Aleša and Maša's article (on some properties of Russian "possessive adjectives.] Scando-Slavica 40, 209-228.

Landman, Fred and Barbara H. Partee (ms.1984): Weak NPs in HAVE sentences. Draft abstract. University of Massachusetts, Amherst.

Larson, Richard and Sungeon Cho (1999): Temporal adjectives and the structure of possessive DPs. In: S. Bird, A. Carnie, J. D. Haugen, and P. Norquest (eds) Proceedings of WCCFL 18, 299-311. Cambridge: Cascadilla Press.

Lyons, Christopher (1986): The syntax of English genitive constructions. Journal of Linguistics 22: 123-143.

Montague, R. (1970): English as a formal language. In: B. Visentini et al (eds.) Linguaggi nella Società e nella Tecnica, 189-224. Milan: Edizioni di Comunità. Reprinted in Montague (1974) 188-221.

- (1973): The Proper Treatment of Quantification in Ordinary English. In: K.J.J. Hintikka, J.M.E. Moravcsik, and P. Suppes (eds.) Approaches to Natural Language, 221-242. Dordrecht: Reidel. Reprinted in Montague (1974) 247-270.

- (1974): Formal Philosophy: Selected Papers of Richard Montague, edited by Richmond Thomason. New Haven: Yale Univ. Press.

Moro, Andrea (1997): The Raising of Predicates. New York: Cambridge University Press.

Munn, Alan (1995): The possessor that stayed close to home. In: V. Samiian and J. Schaeffer (eds.) Proceedings of the Western Conference on Linguistics (WECOL 24), 181-195.

Partee, Barbara H. (1987): Noun phrase interpretation and type-shifting principles. In: J. Groenendijk, D. de Jongh, and M. Stokhof (eds.) Studies in Discourse Representation Theory and the Theory of Generalized Quantifiers, GRASS 8, 115-143. Dordrecht: Foris.

- (1983/1997) Uniformity vs. versatility: the genitive, a case study. Appendix to Theo Janssen (1997), Compositionality. In: Johan van Benthem and Alice ter Meulen (eds.) The Handbook of Logic and Language, 464-470. New York: Elsevier.

- (1999a): Copula inversion puzzles in English and Russian. In: K. Dziwirek et al. (eds.) Formal Approaches to Slavic Linguistics: The Seattle Meeting 1998, Ann Arbor: Michigan Slavic Publications. Also in: Kiyomi Kusumoto and Elisabeth Villalta (eds) UMOP 23: Issues in Semantics and its Interface, 183-208. Amherst: GLSA Publications 2000.

- (1999b): Weak NP's in HAVE sentences. In: Jelle Gerbrandy, Maarten Marx, Maarten de Rijke, and Yde Venema (eds.) A Liber Amicorum for Johan van Benthem on the occasion of his 50th Birthday. Amsterdam.

Partee, Barbara H. / Vladimir Borschev (1998): Integrating lexical and formal semantics: Genitives, relational nouns, and type-shifting. In: R. Cooper and Th. Gamkrelidze (eds.) Proceedings of the Second Tbilisi Symposium on Language, Logic, and Computation, 229-241. Tbilisi: Center on Language, Logic, Speech, Tbilisi State University.

- $\quad$ (in press a): Some puzzles of predicate possessives. To appear in: R.M. Harnish and Istvan Kenesei (eds) Semantics, Pragmatics and Discourse. Perspectives and Connections. A Festschrift for Ferenc Kiefer. Amsterdam: John Benjamins Publishing Company.

- $\quad$ (in press b): Possessives, favorite, and coercion. To appear in: Anastasia Riehl and Rebecca Daly (eds.) Proceedings of ESCOL99, Ithaca, NY: Cornell University Linguistics Students Association

Pustejovsky, James (1993) : Type coercion and lexical selection. In: J. Pustejovsky (ed.) Semantics and the Lexicon, 73-94. Dordrecht:Kluwer.

- $\quad$ (1995): The Generative Lexicon. The MIT Press.

Rappaport, Gilbert (1998): The Slavic noun phrase. [Position paper for Comparative Slavic Morphosyntax]. Available: http://www.indiana.edu/ slavconf/linguistics/download.html [1999, Jan. 4]

Schoorlemmer, Maaike (1995): Participial Passive and Aspect in Russian. Ph.D. dissertation, Utrecht: OTS [Utrecht Institute of Linguistics].

Siegel, Muffy (1976): Capturing the Russian adjective. In: B. Partee (ed.) Montague Grammar, 293-309. New York: Academic Press. 
Stockwell, R.P., P. Schachter and B.H. Partee (1973): The Major Syntactic Structures of English. New York: Holt, Rinehart and Winston.

Szabolcsi, Anna (1994): The Noun Phrase. In: F. Kiefer and K. É.Kiss (eds.) Syntax and Semantics, Vol. 27 [The Syntactic Structure of Hungarian], 179-275. New York: Academic Press.

Vikner, Carl and Per Anker Jensen (ms. 1999): A semantic analysis of the English genitive. Interaction of lexical and formal semantics. Ms, Copenhagen and Kolding, Denmark.

Williams, Edwin (1981): Argument structure and morphology. Linguistic Review 1, 81-114.

- (1983): Semantic vs. syntactic categories. Linguistics and Philosophy 6, 423-446. 